\title{
Acute effect of oral steroids on muscle function in chronic obstructive pulmonary disease
}

\author{
N.S. Hopkinson*, W.D-C. Man*, M.J. Dayer*, E.T. Ross*, A.H. Nickol*, N. Hart*, J. Moxham*, \\ M.I. Polkey*
}

Acute effect of oral steroids on muscle function in chronic obstructive pulmonary disease. N.S. Hopkinson, W.D-C. Man, M.J. Dayer, E.T. Ross, A.H. Nickol, N. Hart, J. Moxham, M.I. Polkey. C ERS Journals Ltd 2004.

ABSTRACT: Prospective data to support the hypothesis that corticosteroids are a significant cause of muscle weakness in patients with chronic obstructive pulmonary disease (COPD) are lacking.

The authors studied respiratory and quadriceps muscle function, using both volitional techniques and magnetic nerve stimulation, as well as measuring metabolic parameters during incremental cycle ergometry, in 25 stable COPD patients. The forced expiratory volume in one second was $37.6 \pm \mathbf{2 1 . 4} \%$ predicted, before and after a 2-week course of o.d. prednisolone $30 \mathrm{mg}$. Quadriceps strength was also assessed in 15 control patients on two occasions.

Only two patients met the British Thoracic Society definition of steroid responsiveness. There was no change either in sniff transdiaphragmatic pressure (pre: $96.8 \pm 19.7 \mathrm{cmH}_{2} \mathrm{O}$; post: $98.6 \pm 22.4 \mathrm{cmH}_{2} \mathrm{O}$ ) or in twitch transdiaphragmatic pressure elicited by bilateral anterolateral magnetic phrenic-nerve stimulation (pre: 16.8 $\pm 9.1 \mathrm{cmH}_{2} \mathrm{O}$; post: $17.9 \pm 10 \mathrm{cmH}_{2} \mathrm{O}$ ). Quadriceps twitch force did not change significantly either in the steroid group (pre: $9.5 \pm 3.1 \mathrm{~kg}$; post: $8.9 \pm 3.7 \mathrm{~kg}$ ) or in the control patients (pre: $8.1 \pm 2.7 \mathrm{~kg}$; post: $7.9 \pm 2.2 \mathrm{~kg}$ ). There were no changes in either peak or isotime ventilatory and metabolic parameters during exercise.

In conclusion, in stable patients with chronic obstructive pulmonary disease, a 2-week course of $30 \mathrm{mg}$ prednisolone daily does not cause significant skeletal muscle dysfunction or alter metabolic parameters during exercise.

Eur Respir J 2004; 24: 137-142.
*Respiratory Muscle Laboratory, Royal Brompton Hospital, and ${ }^{\#}$ Dept of Respiratory Medicine, King's College Hospital, London, UK.

Correspondence: N. Hopkinson, Respiratory Muscle Laboratory, Royal Brompton Hospital, London, SW3 6NP, UK.

Fax: 442073518939

E-mail: n.hopkinson@ic.ac.uk

Keywords: Chronic obstructive pulmonary disease, corticosteroids, diaphragm, exercise, magnetic stimulation, quadriceps

Received: December 162003

Accepted after revision: March 142004

N. Hopkinson is funded by the Wellcome Trust, W. Man by the Medical Research Council, A. Nickol by the British Lung Foundation, E. Ross by the Cystic Fibrosis Trust and M. Dayer by the British Heart Foundation. M. Polkey's COPD research is part of the European Union European network for investigating the global mechanisms of muscle abnormalities in COPD (ENIGMA) Project (Grant no: QLK6-CT-2002-02285).
CUSHING [1] first described the association between excess levels of corticosteroid hormones and skeletal muscle weakness in patients with pituitary adenomas $>70$ yrs ago. Subsequently, with the introduction of corticosteroid therapy for a variety of conditions, it was reported that this treatment could induce a myopathy. Animal studies have confirmed that the administration of high doses of corticosteroid can produce myopathy affecting both ventilatory and peripheral skeletal muscles [2,3].

Chronic obstructive pulmonary disease (COPD) is frequently complicated by locomotor muscle weakness and wasting $[4,5]$ that, in turn, are associated with reduced functional capacity and impaired quality of life [6]. Since these patients are commonly treated with corticosteroids either as "shortburst" therapy for acute exacerbations or as long-term, lowdose "maintenance" therapy, the possibility that corticosteroid treatment might make a significant contribution to the development of weakness has been raised.

In a study of patients admitted with acute exacerbations of airflow obstruction, DECRAMER et al. [7] showed an association between skeletal muscle weakness and the average daily dose of steroids received, mostly as short-burst therapy during acute exacerbations over the preceding 6 months. This group has also described diffuse fibre atrophy, predominantly affecting fast-twitch fibres, in quadriceps biopsies from a population of COPD patients with a clinical diagnosis of steroid-induced myopathy [8]. However, these studies were not able to distinguish the effects of steroid treatment from the effects of previous, frequent exacerbations for which the steroids had been administered.

It has also been reported that patients treated with highdose corticosteroids (average: $61 \mathrm{mg} \cdot \mathrm{day}^{-1}$ prednisolone) for nonrespiratory diseases develop a decrease in respiratory muscle strength and endurance, which resolves over a period of months as the dose of steroids is reduced [9]. A reduction in diaphragm strength has also been demonstrated, following the administration of high-dose methyl prednisolone to treat episodes of acute rejection occurring after lung transplantation [10]. However, two studies in asthma patients have not found evidence of muscle weakness in patients treated with maintenance doses $<40 \mathrm{mg} \cdot \mathrm{day}^{-1}$ of prednisolone $[11,12]$. In healthy subjects, a 2-week course of $20 \mathrm{mg}$ prednisolone $o . d$. did not cause respiratory muscle weakness [13]. Furthermore, the current authors' group has previously demonstrated normal respiratory muscle strength in patients with Cushing's syndrome [14]. Thus, it remains uncertain whether doses of exogenous corticosteroid, typically used to manage patients with COPD, do in fact cause respiratory muscle weakness.

To test the hypothesis that a clinically relevant dose of oral corticosteroids would impair skeletal muscle function in patients with COPD, both volitional and nonvolitional techniques were used to study respiratory muscle and 
quadriceps strength, before and after a standard steroidreversibility trial [15]. In addition, the metabolic and ventilatory parameters at equivalent work rates during cardiopulmonary exercise testing on both occasions were studied.

\section{Methods}

\section{Subjects}

A total of 25 COPD patients (nine females) were recruited, for whom a formal steroid-reversibility trial had been prescribed by their responsible clinician. Steroid responsiveness was defined as an increase of both $200 \mathrm{~mL}$ and $15 \%$ in forced expiratory volume in one second (FEV1) [15]. All subjects performed noninvasive respiratory muscle tests and had measurements of isometric quadriceps strength. As a result of equipment malfunction, quadriceps twitch force was not available for the initial seven steroid trial subjects recruited. A group of 15 stable COPD patients recruited from clinics acted as patient controls. They had measurements of quadriceps maximum voluntary contraction (QuMVC) and twitch quadriceps force (TwQu) performed on two occasions ranging 10-17 days apart. The two groups were well matched in terms of body composition, lung function, age and baseline quadriceps strength. Baseline values were compared to a group of age-matched healthy controls $(n=103)$ recruited by advertisement (table 1). In total, 11 out of 25 of the treatment group and nine out of 15 of the control patients were on regular inhaled corticosteroids, and one of each group was on low-dose $\left(5 \mathrm{mg} \cdot \mathrm{day}^{-1}\right)$ oral prednisolone. Five of the treatment group and none of the controls were taking oral theophylline. Two subjects in the treatment group continued to smoke; five of this group were on long-term oxygen therapy, 16 were taking long-acting $\beta_{2}$ agonists and 15 atrovent. Seven subjects regularly used a nebuliser to administer their bronchodilator therapy.

Patients were excluded if they had had symptoms suggestive of an acute exacerbation in the previous month. The Research Ethics Committee of The Royal Brompton Hospital approved the study. All patients gave written informed consent.

Spirometry, lung volumes and gas transfer corrected for haemoglobin level (Compact Lab System; Jaeger, Bitz, Germany), as well as arterialised capillary blood gas tensions, were measured before and after a 2 -week course of $o . d .30 \mathrm{mg}$

Table 1.-Baseline characteristics of patients and controls

Control patients Steroid trial Healthy controls

\begin{tabular}{lccc}
\hline Subjects n & 15 & 25 & 103 \\
Age yrs & $68.1 \pm 8.2$ & $62.2 \pm 9$ & $61.8 \pm 8.5$ \\
Height cm & $166 \pm 9$ & $171 \pm 8$ & $169 \pm 9$ \\
Weight kg & $65.9 \pm 12$ & $65.7 \pm 14$ & $70.5 \pm 15$ \\
BMI kg m $^{-2}$ & $24.0 \pm 3.6$ & $22.8 \pm 5.7$ & $24.7 \pm 4.0$ \\
FFM kg & $44.6 \pm 7.1$ & $45.5 \pm 5.9$ & $49.7 \pm 12.2^{*}$ \\
FFMI kg m $^{-2}$ & $16.3 \pm 2.1$ & $15.7 \pm 2.0$ & $17.3 \pm 2.8^{*}$ \\
FEV1 L & $0.81 \pm 0.3$ & $1.03 \pm 0.5$ & $2.76 \pm 0.6^{*}$ \\
FEV1 \% pred & $33.8 \pm 15.1$ & $37.6 \pm 21.4$ & $103.2 \pm 14.6^{*}$ \\
TL,CO \% pred & $36.5 \pm 12.8$ & $34.7 \pm 16.5$ & \\
TwQu kg & $8.1 \pm 2.7$ & $9.5 \pm 3.1$ & \\
QuMVC kg & $28.8 \pm 9.1$ & $30.7 \pm 9.6$ & $44.9 \pm 12.9^{*}$ \\
\hline
\end{tabular}

Data are presented as $\mathrm{n}$ and mean $\pm \mathrm{SD}$. Comparisons between patient groups are all $p>0.05$. BMI: body mass index; FFM: fat free mass; FFMI: FFM index; FEV1: forced expiratory volume in one second; $T \mathrm{~L}, \mathrm{CO}$ : carbon monoxide diffusing capacity; TwQu: twitch quadriceps force; QuMVC: quadriceps maximum voluntary contraction. *: $\mathrm{p}<0.05$ for healthy control versus steroid trial group. enteric-coated prednisolone. Patients continued their usual medication throughout. They were specifically advised about the possibility of alterations in mood, sleep and appetite.

Fat free mass (FFM) (kg) was determined using bioelectrical impedance analysis (Bodystat 1500; Bodystat, Isle of Man, UK) and a disease-specific regression equation, where height is measured in $\mathrm{cm}$, resistance in ohm and weight in $\mathrm{kg}$ [16]:

$$
\begin{aligned}
\text { Males: FFM }= & 8.383+\left(\left(0.465 \times \text { height }^{2} / \text { resistance }\right)\right. \\
+ & (0.213 \times \text { weight })) \\
\text { Females: FFM }= & 7.610+\left(\left(0.474 \times \text { height }^{2} / \text { resistance }\right)\right. \\
& +(0.184 \times \text { weight }))
\end{aligned}
$$

This was normalised by dividing by height ${ }^{2}$ to give a FFM index (FFMI). Nutritional depletion was considered to be present if the FFMI was $<15$ for females or $<16$ for males.

\section{Quadriceps strength}

In all subjects seated, QuMVC was measured using the technique of EDWARDS et al. [17]. The maximum force generated during three maximum voluntary contractions with vigorous encouragement was measured. In the last 18 steroid trial subjects and all the control patients, unpotentiated TwQu was also assessed using magnetic femoral nerve stimulation with the patients supine, as the current authors have previously described [18]. Stimuli were delivered, following a 20 -min rest to allow the muscle to depotentiate, using two Magstim 200 monopulse units linked via a Yconnector to a 70-mm branding iron coil (Magstim Ltd, Whitland, UK). The mean of five or more stimulations at $100 \%$ stimulator output was taken. In the last 18 steroid trial patients, the current authors also assessed supine QuMVC with superimposed $100 \%$ stimulations to determine the degree of voluntary activation. If a muscle is maximally activated, a superimposed stimulation should elicit no additional response.

\section{Respiratory muscle strength}

Tests of respiratory muscle strength were performed in the steroid trial subjects only. Five patients declined the use of oesophageal balloon catheters; two were unable to swallow them on their first visit and one further subject on the second visit. Maximum inspiratory $(P \mathrm{I}, \max )$ and expiratory $(P \mathrm{E}, \max )$ mouth pressures [19] were measured, as well as maximum sniff nasal pressure (SNIP) [20]. Oesophageal and gastric pressures were determined using conventionally placed polyethylene catheter-mounted balloons. The current authors measured maximal sniff transdiaphragmatic pressure (Sniff $P$ di) and the unpotentiated response elicited by bilateral anterolateral magnetic phrenic-nerve stimulation (twitch (Tw)Pdi), using a pair of $45-\mathrm{mm}$ branding iron coils each powered by a Magstim 200 monopulse unit (Magstim Ltd) delivering an output $100 \%$ of maximum [21]. Values of TwPdi are reduced at increased lung volumes, so a corrected value was also calculated based on a factor of $5 \mathrm{cmH}_{2} \mathrm{O} \cdot \mathrm{L}^{-1}$ above predicted functional residual capacity (FRC) $[22,23]$.

\section{Exercise testing}

This was only performed in the steroid trial group. In total, 19 out of the 25 patients performed incremental 
symptom-limited cycle ergometry before and after 2 weeks of o.d. $30 \mathrm{mg}$ prednisolone. It was decided not to exercise five patients who were on long-term oxygen therapy and one patient declined to exercise. The protocol involved an initial 2-min rest period, followed by unloaded cycling for $30 \mathrm{~s}$ with increments of $5 \mathrm{~W}$ every $30 \mathrm{~s}$ subsequently. A mouthpiece connected to an Oxycon device (Jaeger) was used for breathby-breath metabolic measurements of oxygen consumption $\left(V^{\prime} \mathrm{O}_{2}\right)$ and $\mathrm{CO}_{2}$ production $\left(V^{\prime} \mathrm{CO}_{2}\right)$. Subjects performed inspiratory capacity manoeuvres every $1 \mathrm{~min}$ to assess dynamic hyperinflation. Peak values after exercise were compared. In addition, to assess performance during equivalent levels of exercise, isotime parameters were compared. Isotime was defined as the last 30 -s period that was completed on both occasions. Every $1 \mathrm{~min}$, subjects were also asked to indicate their level of leg and breathing discomfort on a Borg scale. The reason given for stopping was documented.

\section{Statistical analysis}

Values from before and after steroid therapy and the control group were compared using paired t-tests and between groups using unpaired t-tests. A p-value of $<0.05$ was taken to be significant.

\section{Results}

\section{Baseline values}

The steroid trial patients were significantly weaker and had reduced FFM as compared with healthy controls, although their mean body mass index (BMI) was not significantly different (table 1).

\section{Steroid responsiveness}

The results of pulmonary function tests before and after steroid treatment are given in table 2. Only two patients met the FEV1 criteria for steroid responsiveness. In the group as a whole, there were significant improvements in diffusing capacity, but not in alveolar volume. There were no significant changes in lung volumes obtained by plethysmography. In response to direct questioning, 14 patients $(56 \%)$ reported that their breathing had improved, nine $(36 \%)$ reported that it was the same and two $(8 \%)$ felt that it had worsened. Three patients complained of indigestion, one developed forearm bruising and one developed transient blurred vision. All patients stated that they had complied with 14 days of treatment. Patients who reported an improvement in their breathing did not have a significantly different change in FEV1, transfer factor or FRC, as compared with those reporting no change ( $\mathrm{p}=0.86,0.91$ and 0.64 , respectively).

\section{Quadriceps strength}

In the 25 patients who had a steroid trial, QuMVC increased from $31.4 \pm 9.4$ to $33.8 \pm 10.9 \mathrm{~kg}$; whereas, in the control patients, it increased from $28.8 \pm 9.1$ to $29.9 \pm 9.8 \mathrm{~kg}$ (unpaired t-test, $\mathrm{p}=0.29$ ). Values given in table 3 are for the 18 steroid trial patients and 15 control patients in whom quadriceps twitch was measured. There was no significant change in TwQu in either group (fig. 1). The percentage of voluntary
Table 2. - Lung function before (pre) and after (post) steroid trial

\begin{tabular}{lccc}
\hline & Pre & Post & p-value \\
\hline FEV1 L & $1.03 \pm 0.5$ & $1.04 \pm 0.5$ & $>0.3$ \\
FEV1 \% pred & $37.6 \pm 21.4$ & $38.1 \pm 21.2$ & $>0.3$ \\
TLC L & $7.84 \pm 1.9$ & $7.82 \pm 2.0$ & $>0.3$ \\
TLC \% pred & $127.0 \pm 18$ & $126.3 \pm 17.8$ & $>0.3$ \\
RV L & $4.76 \pm 1.4$ & $4.57 \pm 1.5$ & $>0.3$ \\
RV \% pred & $212.2 \pm 55.8$ & $202.9 \pm 53.7$ & 0.12 \\
RV \% TLC & $60.4 \pm 9.1$ & $58.2 \pm 8.4$ & 0.07 \\
RV \% TLC \% pred & $157 \pm 28$ & $151 \pm 25$ & 0.06 \\
FRC L & $5.89 \pm 1.8$ & $5.9 \pm 1.8$ & $>0.3$ \\
FRC \% pred & $181 \pm 42$ & $179 \pm 41$ & $>0.3$ \\
$T \mathrm{~L}, \mathrm{CO}$ & $3.0 \pm 1.6$ & $3.4 \pm 1.6$ & $0.005^{*}$ \\
$T \mathrm{~L}, \mathrm{CO} \%$ pred & $34.7 \pm 16.5$ & $39.9 \pm 17.4$ & $0.004^{*}$ \\
$V \mathrm{~A} \mathrm{~L}$ & $4.8 \pm 1.1$ & $4.9 \pm 1.1$ & 0.1 \\
$V \mathrm{~A} \%$ pred & $84.9 \pm 14.4$ & $88.1 \pm 14.1$ & 0.07 \\
$K \mathrm{CO} \%$ pred & $43.0 \pm 19$ & $47.7 \pm 20.1$ & $0.002^{*}$ \\
$P \mathrm{a}, \mathrm{CO} \mathrm{kPa}$ & $5.1 \pm 0.8$ & $4.9 \pm 0.9$ & 0.14 \\
$P \mathrm{a}, \mathrm{O}_{2} \mathrm{kPa}$ & $9.8 \pm 1.3$ & $10.2 \pm 1.2$ & $0.05^{*}$ \\
\hline
\end{tabular}

Data are presented as mean $\pm \mathrm{SD}$, unless otherwise stated. FEV1: forced expiratory volume in one second; TLC: total lung capacity; RV: residual volume; FRC: functional residual capacity; TL,CO: carbon monoxide diffusing capacity; $V \mathrm{~A}$ : alveolar volume measured by helium dilution; KCO: carbon monoxide diffusing coefficient; $\mathrm{Pa}_{2} \mathrm{CO}_{2}$ : arterial carbon dioxide tension; $P \mathrm{a}, \mathrm{O}_{2}$ : arterial oxygen tension. *: $\mathrm{p} \leqslant 0.05 ; \mathrm{n}=25$.

Table 3. - Quadriceps strength pre- and post-steroid trial

\begin{tabular}{lccc}
\hline & Pre & Post & p-value \\
\hline Steroid trial $^{\#}$ & & & \\
QuMVC kg & $30.7 \pm 9.6$ & $31.9 \pm 10.7$ & 0.33 \\
Supine QuMVC kg & $33.8 \pm 12.7$ & $35.9 \pm 12.7$ & 0.19 \\
TwQu kg & $9.5 \pm 3.1$ & $8.9 \pm 3.7$ & 0.21 \\
Interpolated TwQu kg & $1.4 \pm 1.4$ & $1.2 \pm 1.5$ & 0.73 \\
Interpolated Tw/supine & $94.7 \pm 5.9$ & $96.0 \pm 5.1$ & 0.44 \\
$\quad$ QuMVC \% & & & \\
Control patients & & & \\
QuMVC kg & $28.8 \pm 9.1$ & $29.9 \pm 9.8$ & 0.54 \\
TwQu kg & $8.1 \pm 2.7$ & $7.9 \pm 2.2$ & 0.46 \\
\hline
\end{tabular}

Data are presented as mean $\pm \mathrm{SD}$, unless otherwise stated. QuMVC: quadriceps maximum voluntary contraction; TwQu: twitch quadriceps force. ${ }^{\#}: \mathrm{n}=18 ;{ }^{\uparrow}: \mathrm{n}=15$.

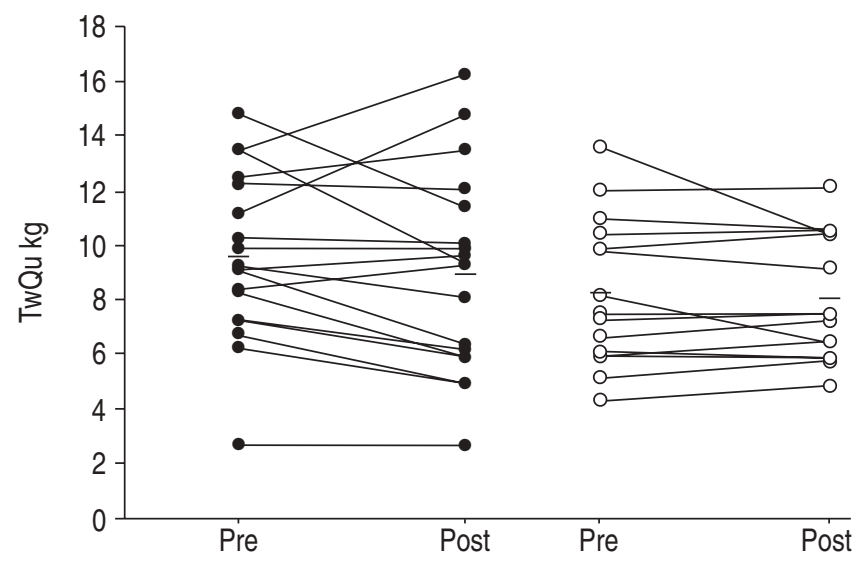

Fig. 1.-Quadriceps twitch force (TwQu) before (pre) and after (post) either prednisolone $(\bullet: n=18)$ or no treatment $(\bigcirc: n=15)$. Horizontal bars represent means. There were no significant changes in TwQu in either group. 
Table 4.-Respiratory muscle strength pre- and post-steroid trial

\begin{tabular}{lcrc}
\hline & Pre $\mathrm{cmH}_{2} \mathrm{O}$ & Post $\mathrm{cmH}_{2} \mathrm{O}$ & p-value \\
\hline Noninvasive tests & & & \\
$\quad$ PI,max & $57.6 \pm 19$ & $64.4 \pm 20$ & $0.03^{*}$ \\
$P$ E,max & $83.8 \pm 38$ & $93.5 \pm 38$ & $0.01^{*}$ \\
$\quad$ SNIP & $64.5 \pm 19$ & $69.7 \pm 20$ & $0.03^{*}$ \\
Invasive tests & & & \\
Sniff $P$ di & $96.8 \pm 19.7$ & $98.6 \pm 22$ & 0.82 \\
Sniff $P$ oes & $70.9 \pm 19.2$ & $72.6 \pm 20$ & 0.97 \\
Cough $P$ gas & $212.5 \pm 62.5$ & $234.5 \pm 55$ & 0.33 \\
TwPdi & $16.8 \pm 9.1$ & $17.9 \pm 10$ & 0.55 \\
TwPdi,corr & $29.4 \pm 11.3$ & $31.0 \pm 13$ & 0.13 \\
\hline
\end{tabular}

Data are presented as mean $\pm \mathrm{SD}$, unless otherwise stated. PI,max: maximum static inspiratory mouth pressure; $P \mathrm{E}$,max: maximum static expiratory mouth pressure; SNIP: sniff nasal pressure; Sniff $P$ di: sniff transdiaphragmatic pressure; Sniff $P$ oes: sniff oesophageal pressure; $P$ gas: gastric pressure; TwPdi: twitch transdiaphragmatic pressure; TwPdi,corr: twitch transdiaphragmatic pressure corrected by $5 \mathrm{cmH}_{2} \mathrm{O} \cdot \mathrm{L}^{-1}$ above predicted functional residual capacity. ${ }^{\#}: \mathrm{n}=25{ }^{*}: \mathrm{n}=17{ }^{*}: \mathrm{p}<0.05$.

activation:

((Supine Qumvc - interpolated TwQu)/Supine Qumvc)

did not change significantly. Individuals' change in TwQu did not correlate with any baseline parameter; specifically age, height, body composition, lung function, exercise parameters or quadriceps strength.

\section{Respiratory muscle strength}

Respiratory muscle strength at baseline was significantly lower in patients as compared with healthy control subjects: $P \mathrm{I}, \max 57.6 \pm 19$ versus $84.5 \pm 26 \mathrm{cmH}_{2} \mathrm{O}, P \mathrm{E}, \max 83.8 \pm 38$ versus $115.5 \pm 43 \mathrm{cmH}_{2} \mathrm{O}$ and SNIP $64.5 \pm 19$ versus $93.1 \pm 22 \mathrm{cmH}_{2} \mathrm{O}$ (all $\mathrm{p} \leqslant 0.001)$.

TwP $\mathrm{di}$ in response to bilateral anterolateral magnetic phrenic nerve stimulation did not change significantly, either as an absolute value or when corrected to the patient's predicted FRC (table 4). There were no significant changes in Sniff $P$ di $\left(96.8 \pm 19.7\right.$ to $\left.98.6 \pm 22 \mathrm{cmH}_{2} \mathrm{O} ; \mathrm{p}=0.82\right)$ or sniff oesophageal pressure (70.9 \pm 19.2 to $\left.72.6 \pm 20 \mathrm{cmH}_{2} \mathrm{O} ; \mathrm{p}=0.97\right)$. There were small significant increases in $P \mathrm{I}, \max (57.6 \pm 19$ to $\left.64.4 \pm 20 \mathrm{cmH}_{2} \mathrm{O} ; \mathrm{p}=0.03\right)$ and $P$ E, $\max (83.8 \pm 38$ to

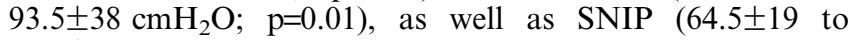
$\left.69.7 \pm 20 \mathrm{cmH}_{2} \mathrm{O} ; \mathrm{p}=0.03\right)$. Maximum cough gastric pressure did not change significantly.

\section{Exercise testing}

There were no significant changes in $V^{\prime} \mathrm{O}_{2}$ and $V^{\prime} \mathrm{CO}_{2}$ or in Borg dyspnoea and leg discomfort scores either at peak exercise or at isotime (table 5). There was no significant difference in the degree of dynamic hyperinflation assessed via changes in inspiratory capacity. Gross metabolic efficiency defined as $\mathrm{O}_{2} \mathrm{~mL}$ consumed per $\mathrm{W}$ was unchanged. On both occasions, nine patients stopped predominantly because of dyspnoea, five because of leg fatigue and five because of a combination of the two.

\section{Discussion}

The main finding of the present study was that, in a group of stable outpatients with moderate-to-severe COPD, a
Table 5. - Exercise parameters pre- and post-steroid trial

\begin{tabular}{|c|c|c|}
\hline & Pre & Post \\
\hline \multicolumn{3}{|l|}{ Peak exercise parameters } \\
\hline Exercise duration $\mathrm{s}$ & $348 \pm 118$ & $370 \pm 135$ \\
\hline Resting inspiratory capacity $\mathrm{L}$ & $2.13 \pm 0.57$ & $2.12 \pm 0.51$ \\
\hline Peak inspiratory capacity L & $1.65 \pm 0.54$ & $1.65 \pm 0.44$ \\
\hline Workload W & $54.0 \pm 20.0$ & $57.6 \pm 22.5$ \\
\hline $\mathrm{O}_{2}$ consumption $\mathrm{L} \cdot \mathrm{min}^{-1}$ & $0.76 \pm 0.22$ & $0.80 \pm 0.2$ \\
\hline $\mathrm{CO}_{2}$ production $\mathrm{L} \cdot \mathrm{min}^{-1}$ & $0.74 \pm 0.25$ & $0.78 \pm 0.2$ \\
\hline Ventilation $\mathrm{L} \cdot \mathrm{min}^{-1}$ & $31.8 \pm 11.5$ & $31.9 \pm 9.9$ \\
\hline Respiratory rate $\min ^{-1}$ & $26.5 \pm 5.9$ & $26.8 \pm 5.4$ \\
\hline Heart rate $\min ^{-1}$ & $107.4 \pm 15.3$ & $108.5 \pm 14.3$ \\
\hline Global efficiency $\mathrm{O}_{2} \mathrm{~mL} \cdot \mathrm{W}^{-1}$ & $15.0 \pm 4.2$ & $14.9 \pm 3.9$ \\
\hline \multicolumn{3}{|l|}{ Isotime exercise parameters } \\
\hline Isotime $\mathrm{s}$ & $306 \pm 119$ & \\
\hline Isotime workload W & $46 \pm 20$ & \\
\hline Inspiratory capacity L & $1.69 \pm 0.55$ & $1.72 \pm 0.39$ \\
\hline $\mathrm{O}_{2}$ consumption $\mathrm{L} \cdot \mathrm{min}^{-1}$ & $0.73 \pm 0.21$ & $0.75 \pm 0.19$ \\
\hline $\mathrm{CO}_{2}$ production $\mathrm{L} \cdot \mathrm{min}^{-1}$ & $0.69 \pm 0.23$ & $0.71 \pm 0.19$ \\
\hline Ventilation $\mathrm{L} \cdot \mathrm{min}^{-1}$ & $30.1 \pm 10.3$ & $30.0 \pm 9.2$ \\
\hline Respiratory rate $\min ^{-1}$ & $26.2 \pm 5.9$ & $24.9 \pm 5.3$ \\
\hline Heart rate $\min ^{-1}$ & $106 \pm 13$ & $105.8 \pm 10.9$ \\
\hline Borg leg discomfort score & $4.0 \pm 1.9$ & $3.9 \pm 2.0$ \\
\hline Borg dyspnoea score & $4.1 \pm 1.4$ & $4.3 \pm 1.4$ \\
\hline Tidal volume $\mathrm{L}$ & $1.1 \pm 0.26$ & $1.2 \pm 0.29$ \\
\hline $\mathrm{O}_{2}$ saturation $\%$ & $94.0 \pm 3.4$ & $93.8 \pm 3.7$ \\
\hline Global efficiency $\mathrm{O}_{2} \mathrm{~mL} \cdot \mathrm{W}^{-1}$ & $17.3 \pm 5.0$ & $18.1 \pm 5.4$ \\
\hline
\end{tabular}

Data are presented as mean \pm SD. All $p>0.05 . n=19$.

2-week course of oral prednisolone does not reduce quadriceps or respiratory muscle strength or impair metabolic parameters during exercise.

\section{Methodological issues}

Appropriateness of steroid trials. At the time this study was undertaken, recommended clinical practice, supported by guidelines from specialist societies including the British Thoracic Society [15], was to perform a formal steroidreversibility trial in patients with COPD to establish the presence of "steroid responsiveness". The utility of this practice was questioned in the 2001 Global Initiative for Chronic Obstructive Lung Disease (GOLD) guidelines [24]. The current authors now believe it should be abandoned, in the light of recent evidence from the Inhaled Steroids in Obstructive Lung Disease in Europe (ISOLDE) study that the response to oral prednisolone does not predict the response to inhaled steroids or subsequent clinical course [25]. Thus, the current authors believe that it is unlikely this study could be repeated.

Patient compliance. The steroid trials were recommended to patients as part of their clinical management, to see if their condition could be optimised. Patients asserted that they had taken their medication and reported a range of changes in symptoms and side-effects, therefore, noncompliance is unlikely to be the explanation for the lack of effect of corticosteroids.

Absence of placebo. Ideally, the hypothesis should have been tested in a randomised placebo-controlled trial. However, in the present study, the clinician responsible for the patient advised a steroid trial and, therefore, the current authors did not consider it justifiable to randomise half the patients not to receive steroid. Conversely, due to the potential side-effects associated with oral corticosteroid treatment, it was felt to be inappropriate to perform the study in patients, except where 
the treatment was clinically indicated. A crossover design would have been problematic due to the uncertain duration of any steroid effects and the invasiveness of the test protocol in a group of relatively disabled patients.

The control group for the quadriceps study underwent no changes in their management during the course of the study. It is possible that there were systematic differences at baseline between the two populations studied, but they were not significantly different in any of the parameters measured. In addition, no factor assessed at baseline predicted change in TwQu after prednisolone.

Response rate. The rate of spirometrically defined steroid responders $(8 \%)$ is consistent with previous studies [26]. Interestingly, on direct questioning, more than half of the patients felt that their breathing had improved. The use of nonvolitional techniques and comparison of isotime, as well as peak metabolic parameters, reduces the risk that any changes in performance detected in the current study might be due to either a placebo effect or the previously described effects of corticosteroids on mood and motivation [27]. In the current study, the absence of a relationship between symptoms and change in lung function parameters highlights the need for objective measurements in this context.

Supramaximality. The validity of measurements of strength based on nerve stimulation depends on the achievement of supramaximality. This is defined as a stimulation intensity above which there is no further increment in response. This can be established by observing a plateau in the stimulus-response curve. In this study, supramaximality of bilateral anterolateral magnetic phrenic nerve stimulation was not formally assessed in order to limit the number of stimulations administered; however, the authors have previously found the technique to be supramaximal or close to supramaximal [21, 28]. The supramaximality of femoral nerve stimulation was formally confirmed in all patients on each occasion.

\section{Significance of the findings}

Effects on muscle strength. The patients studied had significantly reduced measures of respiratory and leg muscle strength as compared with healthy controls, as well as reduced FFM, although their BMI was not significantly different. This confirms the accepted view that quadriceps weakness is a feature of COPD. Nevertheless, the current findings suggest that short-term steroid treatment by itself does not cause further weakness to develop.

For the respiratory muscles, this is consistent with a previous study in healthy subjects, in whom respiratory muscle endurance and maximum mouth pressures were studied [13]. It is also consistent with the current authors' previous observation that patients with Cushing's disease have normal respiratory muscle strength, despite significant quadriceps weakness [14]. One explanation could be that corticosteroid myopathy is known predominantly to affect type-IIb fibres; whereas, the diaphragm in COPD has a preponderance of type-I fibres [29]. Although there were small significant increases in some volitional tests, specifically $P \mathrm{I}, \max$ and $P$ E,max, the authors think that this is likely to represent a learning effect because the values of $\mathrm{Tw} P \mathrm{di}$ and Sniff $P$ di did not change.

The absence of any reduction in quadriceps strength is perhaps more surprising. One problem could be that the technique used for assessing TwQu is insufficiently sensitive. The current authors have previously used the technique to demonstrate low frequency fatigue $[18,30]$, as well as to demonstrate the development of weakness in the unaffected leg following acute hemiplegic stroke [31]. This latter study showed a $22 \%$ reduction in TwQu, which gives an indication of the size of reduction that can occur in a clinically relevant setting. The present study had an $81 \%$ power to detect a $20 \%$ reduction in TwQu. Moreover, the results from interpolated twitches during maximum voluntary contraction confirm that these efforts were close to maximal, and strengthen the finding that there was no reduction in the QuMVC. Additionally, in some cross-sectional studies of patients with COPD, prior corticosteroid treatment has not been found to be related to strength or body composition $[5,32]$. Of note is that other investigators have also failed to identify detrimental effects of steroids on quadriceps [11] or deltoid strength [12] in asthma patients treated with maintenance doses $<40 \mathrm{mg} \cdot$ day $^{-1}$ of prednisolone.

It is possible that steroid treatment could have caused a reduction in muscle endurance rather than strength. However, corticosteroid myopathy is known predominantly to affect type-II fibres. The current authors did not measure endurance or blood lactate directly, but there was no change in $V^{\prime} \mathrm{O}_{2}$ or $V^{\prime} \mathrm{CO}_{2}$ either at isotime or at peak exercise, which argues strongly against an earlier development of lactic acidosis. The absence of change in ventilatory parameters, particularly in dynamic hyperinflation, makes a significant change in work of breathing and, consequently, in the $V^{\prime} \mathrm{O}_{2}$ of the respiratory muscles unlikely. In addition, there was no change in perceived leg discomfort, which also points away from quadriceps muscle dysfunction.

The current results do not directly address the hypothesis that the administration of corticosteroids during an acute exacerbation may contribute to quadriceps weakness. There is certainly good evidence that high doses of corticosteroids can cause skeletal muscle weakness [2]. It is also the case that a previous finding of an association between steroid treatment and weakness in COPD patients was complicated by the fact that steroid administration was almost entirely in the context of acute exacerbations, so that it may simply have been a marker of exacerbation frequency [7]. The dose of prednisolone that was used in this study was similar to that conventionally used to treat acute exacerbations. Therefore, it appears that, in the absence of particular aspects of acute exacerbations of COPD (e.g. systemic inflammation [33, 34] or immobility), short-term treatment with corticosteroids does not itself cause weakness. An interaction is certainly possible as, for example, immobility has been shown to cause an up-regulation of steroid receptors [35]. Moreover, in a recent study of critical illness neuromuscular abnormalities, treatment with corticosteroids was found to be an independent risk factor for the development of weakness [36].

In conclusion, the current findings suggest that, in stable patients, steroid trials are a safe procedure in terms of muscle function. Prospective studies are needed, in order to clarify if short-term courses of corticosteroids do indeed cause a significant loss of muscle strength when administered during acute exacerbations.

\section{References}

1. Cushing H. The basophil adenomas of the pituitary body and their clinical manifestations. Johns Hopkins Med J 1932; 50: 137.

2. Nava S, Gayan-Ramirez G, Rollier H, et al. Effects of acute steroid administration on ventilatory and peripheral muscles in rats. Am J Respir Crit Care Med 1996; 153: 1888-1896.

3. Viires N, Pavlovic D, Pariente R, Aubier M. Effects of steroids on diaphragmatic function in rats. Am Rev Respir Dis 1990; 142: 34-38. 
4. Bernard S, LeBlanc P, Whittom F, et al. Peripheral muscle weakness in patients with chronic obstructive pulmonary disease. Am J Respir Crit Care Med 1998; 158: 629-634.

5. Schols AM, Soeters PB, Dingemans AM, Mostert R, Frantzen PJ, Wouters EF. Prevalence and characteristics of nutritional depletion in patients with stable COPD eligible for pulmonary rehabilitation. Am Rev Respir Dis 1993; 147: $1151-1156$.

6. Hamilton A, Killian K, Summers E, Jones N. Muscle strength, symptom intensity, and exercise capacity in patients with cardiorespiratory disorders. Am J Respir Crit Care Med 1995; 152: 2021-2031.

7. Decramer M, Lacquet L, Fagard R, Rogiers P. Corticosteroids contribute to muscle weakness in chronic airflow obstruction. Am J Respir Crit Care Med 1994; 150: 11-16.

8. Decramer M, de Bock V, Dom R. Functional and histologic picture of steroid-induced myopathy in chronic obstructive pulmonary disease. Am J Respir Crit Care Med 1996; 153: 1958-1964.

9. Weiner P, Azgad Y, Weiner M. The effect of corticosteroids on inspiratory muscle performance in humans. Chest 1993; 104: $1788-1791$

10. Nava S, Fracchia C, Callegari G, Ambrosino N, Barbarito N, Felicetti G. Weakness of respiratory and skeletal muscles after a short course of steroids in patients with acute lung rejection. Eur Respir J 2002; 20: 497-499.

11. Bowyer S, LaMothe M, Hollister J. Steroid myopathy: incidence and detection in a population with asthma. J Allergy Clin Immunol 1985; 76: 234-242.

12. Picado C, Fiz JA, Montserrat JM, et al. Respiratory and skeletal muscle function in steroid-dependent bronchial asthma. Am Rev Respir Dis 1990; 141: 14-20.

13. Wang YM, Zintel T, Vasquez A, Gallagher CG. Corticosteroid therapy and respiratory muscle function in humans. Am Rev Respir Dis 1991; 144: 108-112.

14. Mills GH, Kyroussis D, Jenkins P, et al. Respiratory muscle strength in Cushing's syndrome. Am J Respir Crit Care Med 1999; 160: 1762-1765.

15. The COPD Guidelines Group of the Standards of Care Committee of the BTS. BTS Guidelines for the management of chronic obstructive pulmonary disease. Thorax 1997; 52: Suppl. 5, S1-S28.

16. Steiner MC, Barton RL, Singh SJ, Morgan MD. Bedside methods versus dual energy X-ray absorptiometry for body composition measurement in COPD. Eur Respir J 2002; 19: 626-631.

17. Edwards RHT, Young A, Hosking GP, Jones DA. Human skeletal muscle function: description of tests and normal values. Clin Sci (Lond) 1977; 52: 283-290.

18. Polkey MI, Kyroussis D, Hamnegard CH, Mills GH, Green M, Moxham J. Quadriceps strength and fatigue assessed by magnetic stimulation of the femoral nerve in man. Muscle Nerve 1996; 19: 549-555.

19. Wilson SH, Cooke NT, Edwards RH, Spiro SG. Predicted normal values for maximal respiratory pressures in caucasian adults and children. Thorax 1984; 39: 535-538.

20. Miller JM, Moxham J, Green M. The maximal sniff in the assessment of diaphragm function in man. Clin Sci (Lond) 1985; 69: 91-96.

21. Mills GH, Kyroussis D, Hamnegard CH, Polkey MI, Green
M, Moxham J. Bilateral magnetic stimulation of the phrenic nerves from an anterolateral approach. Am $J$ Respir Crit Care Med 1996; 154: 1099-1105.

22. Criner G, Cordova FC, Leyenson V, et al. Effect of lung volume reduction surgery on diaphragm strength. $A m$ J Respir Crit Care Med 1998; 157: 1578-1585.

23. Polkey MI, Kyroussis D, Hamnegard CH, Mills GH, Green M, Moxham J. Diaphragm strength in chronic obstructive pulmonary disease. Am J Respir Crit Care Med 1996; 154: 1310-1317.

24. Pauwels RA, Buist AS, Calverley PM, Jenkins CR, Hurd SS. Global strategy for the diagnosis, management, and prevention of chronic obstructive pulmonary disease. NHLBI/ WHO global initiative for chronic obstructive lung disease (GOLD) Workshop summary. Am J Respir Crit Care Med 2001; 163: 1256-1276.

25. Burge PS, Calverley PMA, Jones PW, Spencer S, Anderson JA. Prednisolone response in patients with chronic obstructive pulmonary disease: results from the ISOLDE study. Thorax 2003; 58: 654-658.

26. Callahan CM, Dittus RS, Katz BP. Oral corticosteroid therapy for patients with stable chronic obstructive pulmonary disease. A meta-analysis. Ann Intern Med 1991; 114 216-223.

27. Swinburn CR, Wakefield JM, Newman SP, Jones PW Evidence of prednisolone induced mood change ('steroid euphoria') in patients with chronic obstructive airways disease. Br J Clin Pharmacol 1988; 26: 709-713.

28. Man WD, Luo YM, Mustfa N, et al. Postprandial effects on twitch transdiaphragmatic pressure. Eur Respir J 2002; 20 : 577-580.

29. Levine S, Kaiser L, Leferovich J, Tikunov B. Cellular adaptations in the diaphragm in chronic obstructive pulmonary disease. N Engl J Med 1997; 337: 1799-1806.

30. Man WD-C, Soliman MGG, Gearing J, et al. Symptoms and quadriceps fatigability after walking and cycling in chronic obstructive pulmonary disease. Am J Respir Crit Care Med 2003; 168: 562-567.

31. Harris ML, Polkey MI, Bath PM, Moxham J. Quadriceps muscle weakness following acute hemiplegic stroke. Clin Rehabil 2001; 15: 274-281.

32. Engelen MP, Schols AM, Baken WC, Wesseling GJ, Wouters EF. Nutritional depletion in relation to respiratory and peripheral skeletal muscle function in out-patients with COPD. Eur Respir J 1994; 7: 1793-1797.

33. Dentener MA, Creutzberg EC, Schols AM, et al. Systemic anti-inflammatory mediators in COPD: increase in soluble interleukin 1 receptor II during treatment of exacerbations. Thorax 2001; 56: 721-726.

34. Spruit MA, Gosselink R, Troosters T, et al. Muscle force during an acute exacerbation in hospitalised patients with COPD and its relationship with CXCL8 and IGF-I. Thorax 2003; 58: 752-756.

35. DuBois DC, Almon RR. Disuse atrophy of skeletal muscle is associated with an increase in number of glucocorticoid receptors. Endocrinology 1980; 107: 1649-1651.

36. De Jonghe B, Sharshar T, Lefaucheur JP, et al. Paresis acquired in the intensive care unit: a prospective multicenter study. JAMA 2002; 288: 2859-2867. 